\title{
Development of a Novel Quantum Dots and Graphene Oxide Based FRET Assay for Rapid Detection of invA Gene of Salmonella
}

\section{OPEN ACCESS}

Edited by:

Andrea Gomez-Zavaglia

Center for Research

and Development in Food

Cryotechnology - National Scientific and Technical Research Council,

Argentina

Reviewed by:

Maria De Los Angeles Serradell, Centro Científico Tecnológico La

Plata-Consejo Nacional de Investigaciones Científicas y Técnicas - Universidad Nacional

Arturo Jauretche, Argentina

Peter Nagy,

University of Debrecen, Hungary

${ }^{*}$ Correspondence:

Zhenling Zeng

zlzeng@scau.edu.cn

Sheng Chen

sheng.chen@polyu.edu.hk

Specialty section:

This article was submitted to

Food Microbiology,

a section of the journal

Frontiers in Microbiology

Received: 09 August 2016

Accepted: 03 January 2017

Published: 17 January 2017

Citation:

Guo J, Chan EWC, Chen S and

Zeng Z (2017) Development of a Novel Quantum Dots and Graphene Oxide Based FRET Assay for Rapid Detection of invA Gene of Salmonella.

Front. Microbiol. 8:8.

doi: 10.3389/fmicb.2017.00008

\begin{abstract}
Jiubiao Guo ${ }^{1,2}$, Edward W. C. Chan ${ }^{2,3}$, Sheng Chen ${ }^{2,3 *}$ and Zhenling Zeng ${ }^{1 *}$
${ }^{1}$ Guangdong Provincial Key Laboratory of Veterinary Pharmaceutics Development and Safety Evaluation, College of Veterinary Medicine, South China Agricultural University, Guangzhou, China, ${ }^{2}$ Shenzhen Key Lab for Food Biological Safety Control, Food Safety and Technology Research Center, Hong Kong PolyU Shen Zhen Research Institute, Shenzhen, China, ${ }^{3}$ State Key Lab of Chirosciences, Department of Applied Biology and Chemical Technology, Hong Kong Polytechnic

University, Hung Hom, Hong Kong
\end{abstract}

A novel, rapid and simple fluorescence resonance energy transfer (FRET) based Salmonella specific gene, invA, detection system was developed, in which quantum dots (QDs) and graphene oxide (GO) worked as fluorescent donor and quencher, respectively. By measuring the fluorescence intensity signal, the Salmonella specific invA gene could be sensitively and specifically detected with a limit of detection (LOD) of $\sim 4 \mathrm{nM}$ of the invA gene in $20 \mathrm{~min}$. The developed system has the potential to be used for Salmonella detection in food and environmental samples and further developed into a platform for detection of other bacterial pathogens.

\section{Keywords: Salmonella, invA, quantum dots, graphene oxide, FRET assay, rapid detection}

\section{INTRODUCTION}

Salmonella, a major Gram-negative bacteria enteric pathogen, has evolved numerous strategies to infect and proliferate in a vast array of hosts, such as humans and animals, causing a wide range of food- and water-borne diseases (LaRock et al., 2015). It is estimated that Salmonella resulted in 17,000 hospitalization and 585 deaths each year in the US, causing \$2.3-3.6 billion economic lost annually (Foley and Lynne, 2008). There is an urgent need for rapid and sensitive detection methods of Salmonella, especially methods that do not require sophisticated equipment or intensive labor, to prevent outbreaks and recalls due to Salmonella contamination.

Salmonella culture-based detection strategies are time-consuming and labor intensive, although they are the main methods for diagnosis (Okamura et al., 2008). Real-time PCR (rt-PCR; HaraKudo et al., 2005) methods can detect Salmonella by measuring the increased fluorescence via the amplification of DNA; the loop-mediated isothermal amplification (LAMP) strategy (Techathuvanan et al., 2011) which relies on autocycling strand displacement DNA synthesis is novel, rapid and simple, but they suffer from expensive equipment and depend on skillful technicians, etc. The last decade has witnessed a rapid development of biosensing techniques and new biomaterials (Saikia et al., 2013; Jana et al., 2015; Unser et al., 2015; Zheng et al., 2015). They have been proven to be valid for various applications ranging from pathogens detection to cancers therapies (Alocilja and Radke, 2003; Liu et al., 2009; Chen et al., 2015; Shi et al., 2015). Graphene is the first two-dimensional atomic crystal discovered, and chemically derived graphene oxide (GO) is served as a precursor for grapheme. $\mathrm{GO}$ is an atomically thin sheet with large 
surface area, possibility of easy functionalization by various functional groups, and long-range resonance energy transfer distance, which make it an ideal quencher in bioapplications (Loh et al., 2010; Novoselov et al., 2012). Recently, the semiconductor, quantum dots (QDs), is considered as one of the most promising emerging fluorescent dyes. When compared with conventional dyes, QDs display superior features such as photobleaching resistance, narrow, symmetric and size-tunable absorption and emission wavelength (Wu et al., 2003; Dong et al., 2010). Due to these interesting properties, QDs have been widely used in biological applications (Medintz et al., 2005; Lu et al., 2011; Saikia et al., 2013; Wu et al., 2015). In addition, a few studies have reported the combination usage of GO and QDs in detecting and sensing biomolecules (Liao et al., 2014). InvA gene, one of the virulence chromosomal genes, has been proved to be unique to Salmonella and can be used as a suitable PCR target for the detection of Salmonella (Rahn et al., 1992; Zahraei Salehi et al., 2005; Shanmugasamy et al., 2011). In addition, an invA targeted isothermal target and probe amplification (iTPA) approach has been applied by Kim et al. (2011) for the specific and rapid detection of Salmonella. But few studies present rapid and sensitive invA gene detection in Salmonella by combinational usage of GO and QDs as fluorescence resonance energy transfer (FRET) pair (Lee et al., 2015; Zhang et al., 2016).

In the present work, an assay based on FRET pair between QDs and GO technology was developed to target the highly conserved invA gene of Salmonella for the purpose of rapid and sensitive detection of this important pathogen (Zahraei Salehi et al., 2005).

\section{MATERIALS AND METHODS}

\section{Reagents and Materials}

Graphene oxide was a kind gift from Dr. Yang's lab (The Hong Kong Polytechnic University, HK, China). Carboxylmodified 525nm QDs were purchased from Invitrogen, Ltd. (USA). Phosphate buffered saline (PBS) pH 7.4 and bovine serum albumin (BSA) were prepared accordingly. N-hydroxysuccinimide (NHS) and 1-ethyl-3-(3-dimethylaminopropyl) carbodiimide hydrochloride (EDC) were purchased from SigmaAldrich (St. Louis, MO, USA). Microcon molecular weight cut-off (MWCO) spin filters were obtained from Millipore Corporation (Bedford, MA, USA). Luria Bertani (LB) broth was purchased from Qingdao Hope Bio-Technology Co., Ltd. (China) and prepared by following supplier's instruction. DNA extraction kits were purchased from Qiagen (Germany). A 30-mer single strand invA oligo (5'-CTTTCGTCTGGCA TTATCGATCAGTACCAG-3') and a 26-mer single strand control oligo (5'-GTGAAATTATCGCCACGTTCGGGCAA-3') were extracted from the highly conserved Salmonella typhimurium invA gene (GenBank: M90846.1). Single-base mismatched oligo (M1: 5' -CTTTCGTGTGGCATTATCGATCAGTACC AG-3'), double-base mismatched oligo (M2: 5'-CTTTCGTGT GGCATTATCCATCAGTACCAG-3') and the control oligo were synthesized for the specificity test of the developed system. Amine-modified capture A (5'-ATGCCAGACGAAAG/ Aminolinker $\left.\mathrm{C} 7 /-3^{\prime}\right)$ and capture B (5'-/Aminolinker C6/CTG GTACTGATCGA-3') that were complementary to the invA oligo were designed and synthesized. The primers that can specifically amplify the desired part of the invA gene were synthesized as well. The sequence of the forward primer is F-invA: GCCTACAAGCATGAAATGGCAGAAC and the reverse primer is R-invA: TCATCGCACCGTCAAAGGAACC. The length of the amplified product is about $649 \mathrm{bp}$. All the oligonucleotides listed in Table 1 were synthesized by Beijing Genomics Institute (Shenzhen, Guangdong, China) and prepared according to the supplier's instruction.

\section{InvA Fragment Preparation}

Salmonella Typhimurium (S. Typhimurium) was inoculated in LB broth and maintained at $37^{\circ} \mathrm{C}$ overnight. $1.5 \mathrm{~mL}$ of the overnight culture was used to extract genomic DNA and suspended into $50 \mu \mathrm{L}$ distilled water with a concentration of $0.6 \mu \mathrm{g} / \mu \mathrm{L} .0 .5 \mu \mathrm{L}$ of the extracted Salmonella genomic DNA $(\sim 0.3 \mu \mathrm{g})$ was used as template for PCR reaction. $10 \mu \mathrm{L}$ of the purified PCR products $(100 \mathrm{ng} / \mu \mathrm{L})$ were used for the following detection analysis.

\section{Conjugation of GO and QDs with Probes}

The process of conjugation between GO or QDs with capture A or B was realized by EDC/NHS assisted covalent bonding where EDC [1-Ethyl-3-(3-dimethylaminopropyl)carbodiimide] is a zero-length cross-linking agent used to couple carboxyl or phosphate groups to primary amines and NHS (hydroxysuccinimide) was used as a stabilizer. The conjugation between GO and capture A was performed as described in a previous study where capture A was derived from the positive strand of and complementary to Salmonella invA gene (Shi et al., 2015). Briefly, freshly prepared NHS (5 mM) and EDC (1 mM) were added into the GO solution $(5 \mathrm{mg} / \mathrm{mL})$, vortex for $2 \mathrm{~min}$ and sonication for $15 \mathrm{~min}$. Then the treated GO was mixed with $30 \mu \mathrm{M}$ capture $\mathrm{A}$, sonicated at room temperature (RT) for $1 \mathrm{~h}$. The generated GO-capture A conjugate was further purified and washed by DI- $\mathrm{H}_{2} \mathrm{O}$ by centrifugation at RT at $10,000 \mathrm{rpm}$ for several times. In order to prevent unspecific binding of QDs with GO-capture A, the GO-capture A conjugate was further treated with $0.5 \mathrm{mg} / \mathrm{mL}$ BSA at RT for $30 \mathrm{~min}$ and then rinsed with $\mathrm{DI}-\mathrm{H}_{2} \mathrm{O}$.

TABLE 1 | The DNA sequences of synthesized oligonucleotides in this study.

\begin{tabular}{lc}
\hline Oligos/Primers & Sequence $\left(\mathbf{5}^{\prime} \mathbf{-} \mathbf{3}^{\prime} \mathbf{)}\right.$ \\
\hline invA oligo & CTTCGTCTGGCATTATCGATCAGTACCAG \\
Control oligo & GTGAATTATCGCCACGTTCGGGCAA \\
M1 & CTTCGTGTGGCATTATCGATCAGTACCAG \\
M2 & CTTCGTGTGGCATTATCCATCAGTACCAG \\
Capture A & ATGCCAGACGAAAG/Aminolinker C7 \\
Capture B & Aminolinker C6/CTGGTACTGATCGA \\
F-invA & GCCTACAAGCATGAATGGCAGAAC \\
R-invA & TCATCGCACCGTCAAAGGAACC
\end{tabular}


For the conjugation of QDs with capture B, which was derived from positive strand of and complementary to Salmonella invA gene, most of the procedures were carried out following the manufactures' instructions, but with modifications. $50 \mu \mathrm{l}$ QDs stock solution $(8 \mu \mathrm{M})$ was diluted in $1 \mathrm{xPBS}$ ( $\mathrm{pH} 7.4)$, mixed with $20 \mu \mathrm{M}$ capture $\mathrm{B}$, followed by immediate addition of EDC ( $1 \mathrm{mg} / \mathrm{mL})$. The mixture was then mixed by rotating at RT at dark environment for $2 \mathrm{~h}$. The unbound capture B was removed by using a centrifugal filter and then washed by $1 \mathrm{xPBS}(\mathrm{pH} 7.4)$ for several times. $0.1 \% \mathrm{~N}_{3} \mathrm{Na}$ was added in the final products and stored at $4^{\circ} \mathrm{C}$ in dark environment for future use.

\section{Characterization}

Fourier transform infrared spectrum (FT-IR) spectra of GO, GO-capture A, QDs and QD-capture B were measured with a PerkinElmer Spectrum 100 FT-IR spectrometer (PerkinElmer Inc., USA). Zeta potentials of GO, GO-capture A, QDs and QD-capture B were characterized by a ZetaPlus Zeta Potential Analyzer (Brookhaven Instruments Corp., USA).

\section{Fluorimetric Assay}

In the system, the invA oligo worked as a bridge to bring the GOcapture A and QD-capture B conjugates close enough by being complementary to both capture $\mathrm{A}$ and $\mathrm{B}$, the energy emitted by QDs would be quenched by GO in the form of decreased fluorescence intensity. $0.5 \mathrm{mg} / \mathrm{mL}$ BSA passivated GO-capture A $(60 \mu \mathrm{g} / \mathrm{mL})$ was first mixed with invA oligo and incubated at $55^{\circ} \mathrm{C}$ for $10 \mathrm{~min}$, then a desired concentration of QD-capture $\mathrm{B}(150 \mathrm{nM})$ was added, the mixture was incubated at $55^{\circ} \mathrm{C}$ for another $10 \mathrm{~min}$. The total reaction volume was $50 \mu \mathrm{l}$. The fluorescence intensity was measured by using a Cary Eclipse Fluorescence Spectrophotometer (Agilent Technologies, USA) with the excitation wavelength set as $320 \mathrm{~nm}$ and emission range as $480-580 \mathrm{~nm}$. For the specificity test of the system, the invA oligo was replaced either by M1 or M2 or control oligo in the reaction mixture, and for the application assay of the developed system, the relative PCR product was added in the place of invA oligo. All the assays were repeated for at least five times.

\section{Statistical Analysis}

Standard Error of the Mean (SEM) was used to express the error in replicates. For group comparisons, the statistical test used was unpaired two-tailed $t$-test $(P<0.05)$. The statistical analyses were performed with GraphPad Prism 5 (GraphPad Software, Inc., USA).

\section{RESULTS AND DISCUSSION}

\section{Principal of the Salmonella invA Gene Detection System}

The invA gene of Salmonella is highly conserved and has been used as a target for the detection of Salmonella previously (Zahraei Salehi et al., 2005). The principle of the developed Salmonella invA gene detection system is illustrated in Figure 1. In the system, carboxyl QDs (donor) and GO (quencher) were first conjugated with the capture $\mathrm{B}$ and $\mathrm{A}$, respectively, with the aid of EDC/NHS. Upon the addition of the complementary invA oligo of Salmonella, the QDs and GO conjugates could be brought into close proximity to make the FRET pair work, the energy emitted from excited QDs would be quenched by GO. Based on this mechanism, the invA gene of Salmonella can be detected via the measurement of the fluorescence intensity change in the developed system.

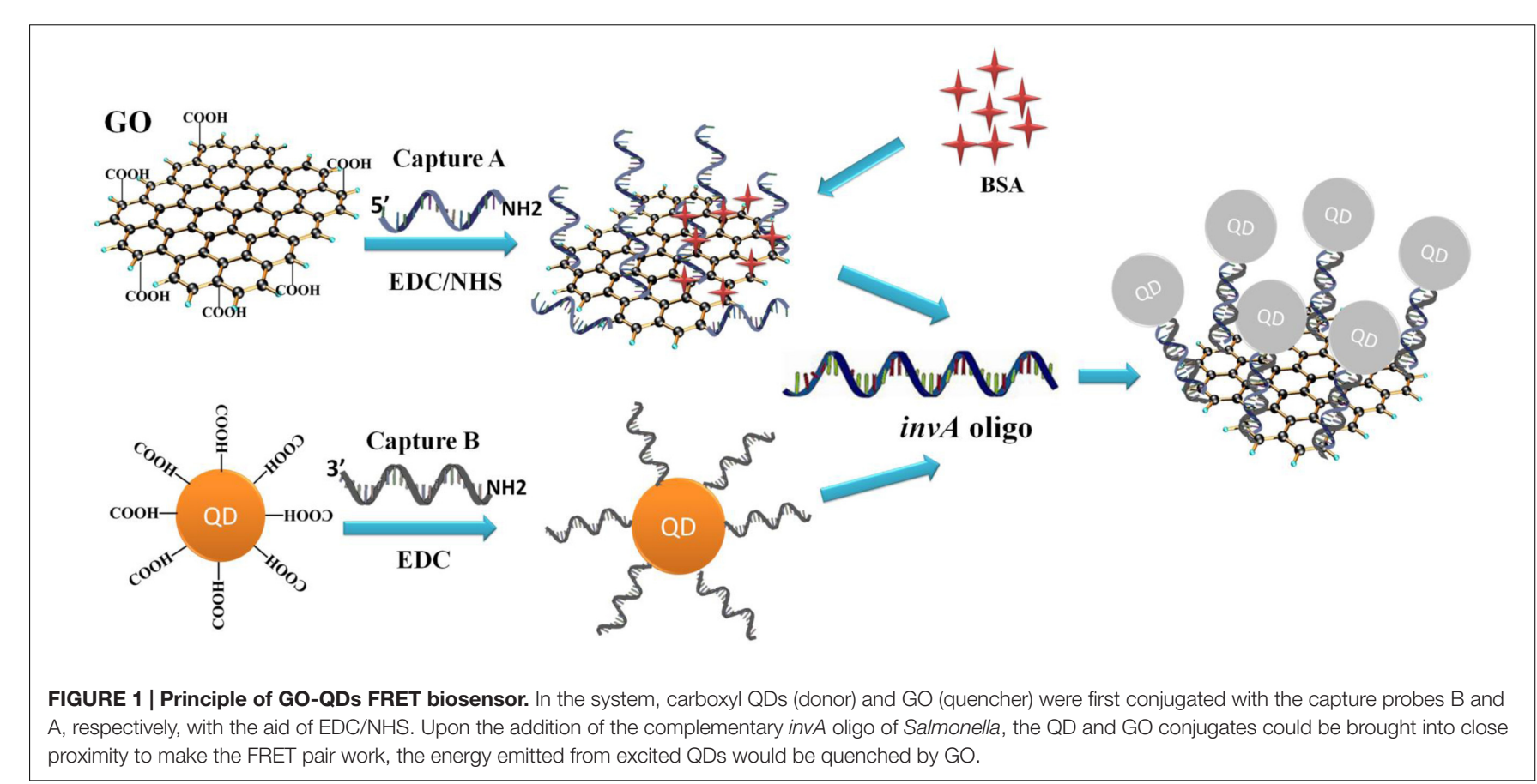




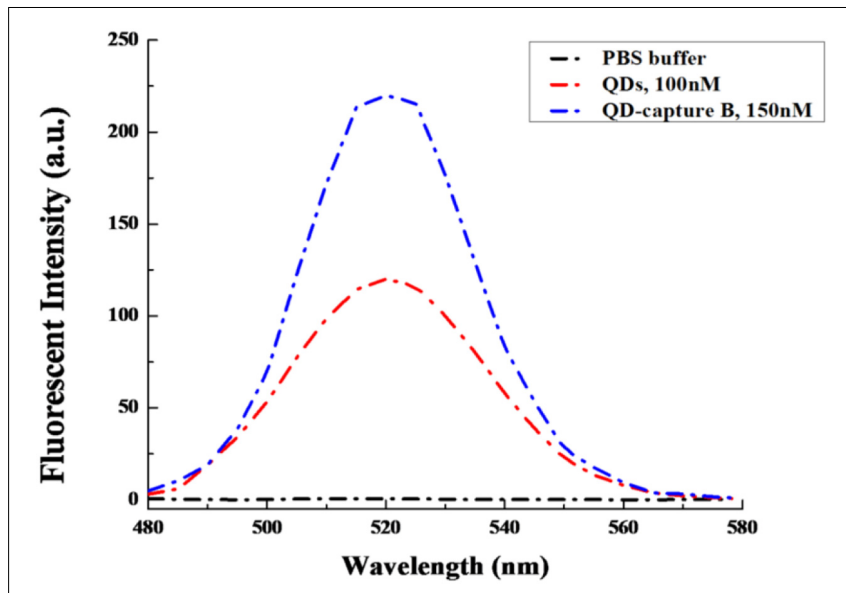

FIGURE 2 | The emission spectra comparison between QDs and QD-capture B conjugate. The QD and QD-capture B conjugate were diluted in 1xPBS, $\mathrm{pH}=7.4$. The excitation wavelength was set at $320 \mathrm{~nm}$.

\section{Characterization of GO and QDs}

After conjugation of GO and QDs with the corresponding oligonucleotides, the conjugates of GO-capture A and QDcapture B were analyzed by zeta potentials. When compared with that of GO, the zeta potential value of GO-capture A was about $-25 \mathrm{mV}$, much closer to that of capture A alone, and both zeta potential peaks overlapped (Supplementary Figure S1A); so did the QD-capture B zeta potential value, which was about $-12.5 \mathrm{mV}$, closer and overlapped with that of capture $\mathrm{B}$ alone as well (Supplementary Figure S1B), indicating that the surface of GO and QDs were covered by the corresponding captures after conjugation. In addition, the successful conjugation between GO and capture A or QDs and capture B were confirmed by FTIR spectra analysis as shown in Supplementary Figure S2. The characteristic amide vibration absorption peak could be obviously detected at around $1655 \mathrm{~cm}^{-1}$ both in GO-capture A (Supplementary Figure S2A) and QD-capture B (Supplementary Figure S2B), suggesting that an amide bond has formed between the carboxyl group on GO or QDs and the amine group of oligonucleotides.

Moreover, in order to check whether the capture B oligo could alter the emission pattern of QDs or not under the excitation wavelength of $320 \mathrm{~nm}$, the emission spectra of QDs and QDcapture B were compared, and both of them were found to display very similar emission patterns with the emission peak at about $520 \mathrm{~nm}$ (Figure 2).

\section{FRET Biosensor for invA Detection}

Graphene oxide has relatively large surface area for binding but does not exhibit binding specificity. In order to reduce or avoid undesired interaction between GO and QD conjugates, the GO conjugates were first passivated by BSA. After passivation, the non-specific interaction between GO and QD conjugates could be decreased but could not be completely avoided (Figure 3A). To investigate the quenching efficiency of developed biosensor in the detection of invA gene, experimental and control assays were

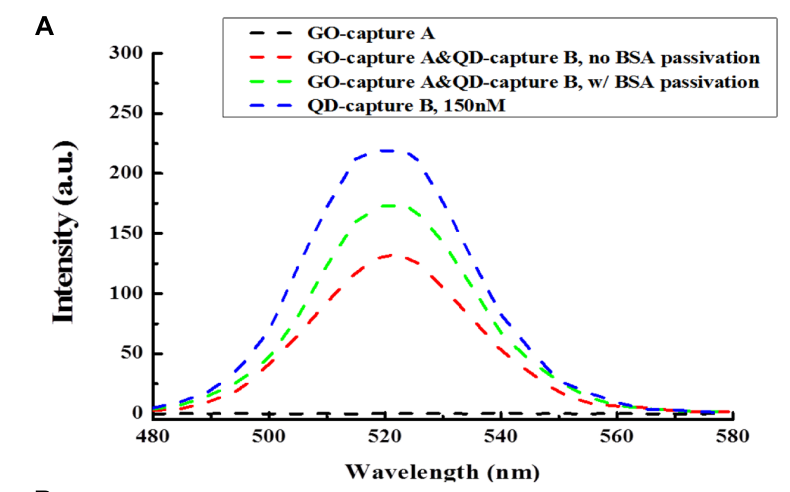

B

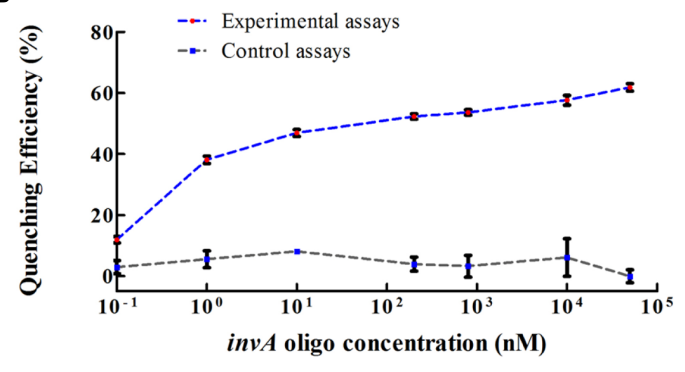

FIGURE 3 | The BSA passivation effect and quenching efficiency of the developed invA gene biosensor. (A) The BSA passivation effect in decreasing the non-specific adsorption between $\mathrm{GO}$ and $\mathrm{QD}$ conjugates. Briefly, in order to check the BSA passivation effect in preventing unspecific binding between $\mathrm{QD}$ and $\mathrm{GO}$ conjugates, the GO-capture A conjugate was further treated with or without $0.5 \mathrm{mg} / \mathrm{mL}$ BSA at RT for $30 \mathrm{~min}$ and then rinsed with $\mathrm{DI}-\mathrm{H}_{2} \mathrm{O}$, then the fluorescence intensity was measured. The data were analyzed by OriginPro 8.5. (B) For the quenching efficiency assays, in $50 \mu$ l reaction volume, BSA passivated GO-capture A (60 $\mu \mathrm{g} / \mathrm{mL})$ was first incubated with serially diluted invA oligo at $55^{\circ} \mathrm{C}$ for $10 \mathrm{~min}$, then $150 \mathrm{nM}$ $\mathrm{QD}$-capture B was added to the reaction mixture and incubated at $55^{\circ} \mathrm{C}$ for another $10 \mathrm{~min}$. The fluorescence intensity was measured under $320 \mathrm{~nm}$ excitation wavelength and the values at $520 \mathrm{~nm}$ were extracted for the calculation of quenching efficiency. The only difference between the experimental assays and the control assays was that the BSA passivated GO-capture A which was included in the experimental assays was replaced by BSA passivated GO (without capture A) in the control assays. The SEM (Standard Error of the Mean) error bars were calculated from at least three replicates. The data were analyzed by GraphPad Prism.

carried out. In the experimental assays, various concentration of synthesized $i n v A$ oligo was studied with the passivated GOcapture A concentration fixed at $60 \mu \mathrm{g} / \mathrm{mL}$, in the control assays, the only difference was that the passivated GO-capture A was replaced by the same concentration of passivated GO (without capture A). Theoretically, before saturation, the higher concentration of the invA oligo included in the reaction mixture, the higher quenching efficiency would be observed. The formula of quenching efficiency is $\mathrm{Q}=(\mathrm{F} 0-\mathrm{Fq}) / \mathrm{F} 0^{*} 100 \%$, in which the $F_{0}$ represents the fluorescence intensity of QD-capture B before quenching and the $F_{\mathrm{q}}$ means that after quenching. About $50 \%$ quenching efficiency could be detected with as low as $10 \mathrm{nM}$ invA oligo, but the quenching efficiency was not increased significantly with the higher concentration of invA oligo. For comparison, in the control assays, almost no quenching efficiency 


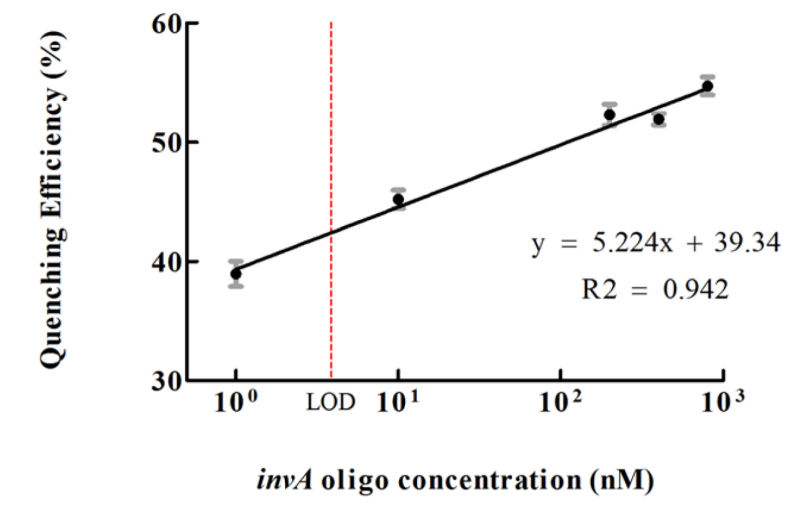

FIGURE 4 | The limit of detection (LOD) of the developed invA gene biosensor. The quenching efficiencies which were calculated as according to the listed formula were potted versus different concentrations of invA oligo. $\mathrm{LOD}=3^{*} \mathrm{~S} / \mathrm{k}$ (S means standard deviation of negative control, $k$ means slope). The SEM (Standard Error of the Mean) error bars were calculated from at least three replicates.

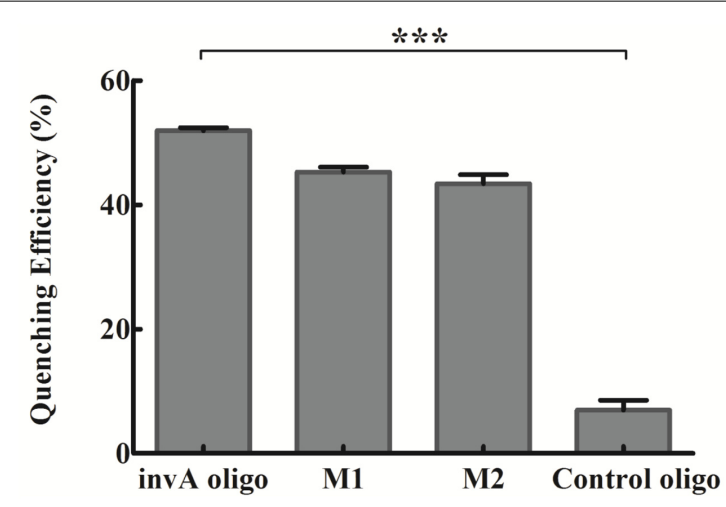

FIGURE 5 | The specificity of the developed invA gene biosensor. The concentrations of invA oligo (fully complementary to probes), M1 (one-base mismatch), M2 (two-base mismatch) and control oligo (not complementary to neither probes) used were fixed at $400 \mathrm{nM}$. The SEM (Standard Error of the Mean) error bars were calculated from at least three replicates. The difference between invA oligo and control oligo groups was significant $(P<0.0001$, two tail $t$-test), but the difference between invA oligo and M1 or M2 groups were not significant $(P>0.05$, two tail $t$-test). The data was analyzed by GraphPad Prism. ${ }^{* * *} P<0.0001$

could be detected (Figure 3B). The limit of detection (LOD) of the present system in detecting invA gene of Salmonella was further determined which was $\sim 4 \mathrm{nM}$ (Figure 4).

The biosensor specificity in detecting invA gene of Salmonella was analyzed by using mismatched oligonucleotides and control oligo. The quenching efficiency of $400 \mathrm{nM}$ invA oligo was $\sim 52 \%$, and that of $400 \mathrm{nM} \mathrm{M} 1$ and M2 were $\sim 45$ and $\sim 43 \%$, respectively, while that of control oligo was smaller than $10 \%$, a significant difference from invA oligo $(P<0.0001$, two-tailed $t$-test; Figure 5), suggesting that the system is very specific for detecting invA gene, while its discrimination power is not very high when the oligo is within couple of nucleotide difference from invA gene. Consistently, a higher selectivity was reported

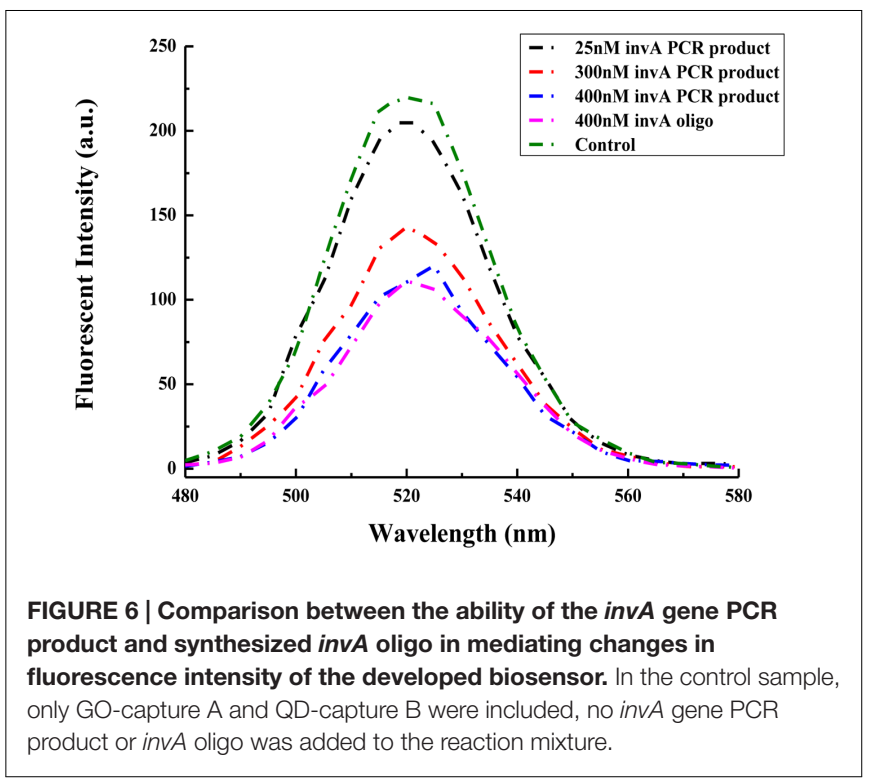

by applying similar detection approaches (Yang et al., 2008; Shi et al., 2015). In addition, J.S. Kim and colleagues witnessed very high Salmonella spp. detection specificity by using invA gene as target, with all of 10 Salmonella spp. could be specifically detected, but not the 40 non-Salmonella strains (Kim et al., 2011).

\section{The Possible Application of the Developed invA Gene Detection Biosensor}

The invA gene has previously been used as target to specifically detect Salmonella spp. in food samples with high sensitivity (Kim et al., 2011). In order to check the possibility of the present biosensor in detecting the invA gene from Salmonella of environmental samples, specific primers were used to amplify the invA gene which cover the complementary fragment of probes that are conjugated onto GO and QDs. Compared with the same concentration of the invA oligo, $400 \mathrm{nM}$ PCR product of invA gene could cause almost same degree of decrease in fluorescent intensity, and the fluorescent intensity varied accordingly with the change of the concentrations of PCR product of invA gene. The fluorescence intensity pattern from using $25 \mathrm{nM}$ PCR product was almost the same as that of control assay, and for the assay with $300 \mathrm{nM}$ PCR product, the intensity peak (around $520 \mathrm{~nm}$ ) was about half of that from the control assay (Figure 6), indicating that the present biosensor has the potential to be applied in detecting the invA gene of Salmonella in food or environmental samples.

\section{CONCLUSION}

Salmonella infections continue to be a major public health threat worldwide. To achieve efficient and timely prevention of Salmonella outbreaks, new detection methods featured by rapidness, high sensitivity and simplicity of operation are prerequisite. In the present study, a novel Salmonella detection 
system based on the highly conserved invA gene was developed by utilizing nanomaterials of QDs and GO and the FRET technology. After careful measurement and evaluation, the reported system could specifically detect as low as $\sim 4 \mathrm{nM}$ invA gene of Salmonella. The use of QDs to pair with GO could significantly improve the sensitivity and signal stability and could be potentially applied for in-field Salmonella detection to ensure food safety. Further study will be carried out to investigate the feasibility and detection efficiency of the developed biosensor in detecting Salmonella spp. directly in food samples, and the convenience for in-field Salmonella detection in the near future.

\section{AUTHOR CONTRIBUTIONS}

JG designed, conducted the experiments, analyzed the data, and wrote the manuscript. EC designed the experiment and edited the manuscript. SC and ZZ initiated and supervised the project, and edited the manuscript.

\section{REFERENCES}

Alocilja, E. C., and Radke, S. M. (2003). Market analysis of biosensors for food safety. Biosens. Bioelectron. 18, 841-846. doi: 10.1016/s0956-5663(03) 00009-5

Chen, H., Wang, Z., Zong, S., Chen, P., Zhu, D., Wu, L., et al. (2015). A graphene quantum dot-based FRET system for nuclear-targeted and realtime monitoring of drug delivery. Nanoscale 7, 15477-15486. doi: 10.1039/ c5nr03454j

Dong, H., Gao, W., Yan, F., Ji, H., and Ju, H. (2010). Fluorescence resonance energy transfer between quantum dots and graphene oxide for sensing biomolecules. Anal. Chem. 82, 5511-5517. doi: 10.1021/ac100852z

Foley, S. L., and Lynne, A. M. (2008). Food animal-associated Salmonella challenges: pathogenicity and antimicrobial resistance. J. Anim. Sci. 86(14 Suppl.), E173-E187. doi: 10.2527/jas.2007-0447

Hara-Kudo, Y., Yoshino, M., Kojima, T., and Ikedo, M. (2005). Loop-mediated isothermal amplification for the rapid detection of Salmonella. FEMS Microbiol. Lett. 253, 155-161. doi: 10.1016/j.femsle.2005.09.032

Jana, D., Matti, C., He, J., and Sagle, L. (2015). Capping agent-free gold nanostars show greatly increased versatility and sensitivity for biosensing. Anal. Chem. 87, 3964-3972. doi: 10.1021/acs.analchem.5b00014

Kim, J. S., Jahng, M. S., Lee, G. G., Lee, K. J., Chae, H. K., Lee, J. H., et al. (2011). Rapid and simple detection of the invA gene in Salmonella spp. by isothermal target and probe amplification (iTPA). Lett. Appl. Microbiol. 52, 399-405. doi: 10.1111/j.1472-765X.2011. 03018.x

LaRock, D. L., Chaudhary, A., and Miller, S. I. (2015). Salmonellae interactions with host processes. Nat. Rev. Microbiol. 13, 191-205. doi: 10.1038/nrmicro 3420

Lee, K.-M., Runyon, M., Herrman, T. J., Phillips, R., and Hsieh, J. (2015). Review of Salmonella detection and identification methods: aspects of rapid emergency response and food safety. Food Control 47, 264-276. doi: 10.1016/j.foodcont. 2014.07.011

Liao, Y., Zhou, X., and Xing, D. (2014). Quantum dots and graphene oxide fluorescent switch based multivariate testing strategy for reliable detection of Listeria monocytogenes. ACS Appl. Mater. Interfaces 6, 9988-9996. doi: 10. 1021/am503230h

Liu, G., Mao, X., Phillips, J. A., Xu, H., Tan, W., and Zeng, L. (2009). Aptamernanoparticle strip biosensor for sensitive detection of cancer cells. Anal. Chem. 81, 10013-10018. doi: 10.1021/ac901889s

Loh, K. P., Bao, Q., Eda, G., and Chhowalla, M. (2010). Graphene oxide as a chemically tunable platform for optical applications. Nat. Chem. 2, 1015-1024. doi: $10.1038 /$ nchem.907

\section{FUNDING}

This work was supported by the Chinese National Key Basic Research and Development (973) Program (2013CB127200).

\section{ACKNOWLEDGMENT}

We are grateful to the technical assistance from the lab of Mo Yang in PolyU.

\section{SUPPLEMENTARY MATERIAL}

The Supplementary Material for this article can be found online at: http://journal.frontiersin.org/article/10.3389/fmicb. 2017.00008/full\#supplementary-material

Lu, Z., Zhu, Z., Zheng, X., Qiao, Y., Guo, J., and Li, C. M. (2011). Biocompatible fluorescence-enhanced $\mathrm{ZrO}(2)-\mathrm{CdTe}$ quantum dot nanocomposite for in vitro cell imaging. Nanotechnology 22:155604. doi: 10.1088/0957-4484/22/15/155604 Medintz, I. L., Uyeda, H. T., Goldman, E. R., and Mattoussi, H. (2005). Quantum dot bioconjugates for imaging, labelling and sensing. Nat. Mater. 4, 435-446. doi: $10.1038 /$ nmat 1390

Novoselov, K. S., Fal'ko, V. I., Colombo, L., Gellert, P. R., Schwab, M. G., and Kim, K. (2012). A roadmap for graphene. Nature 490, 192-200. doi: 10.1038/ nature 11458

Okamura, M., Ohba, Y., Kikuchi, S., Suzuki, A., Tachizaki, H., Takehara, K., et al. (2008). Loop-mediated isothermal amplification for the rapid, sensitive, and specific detection of the O9 group of Salmonella in chickens. Vet. Microbiol. 132, 197-204. doi: 10.1016/j.vetmic.2008.04.029

Rahn, K., De Grandis, S. A., Clarke, R. C., McEwen, S. A., Galan, J. E., Ginocchio, C., et al. (1992). Amplification of an invA gene sequence of Salmonella typhimurium by polymerase chain reaction as a specific method of detection of Salmonella. Mol. Cell. Probes 6, 271-279. doi: 10.1016/08908508(92)90002-F

Saikia, K., Deb, P., and Kalita, E. (2013). Sensitive fluorescence response of ZnSe(S) quantum dots: an efficient fluorescence probe. Phys. Scr. 87. doi: 10.1088/00318949/87/06/065802

Shanmugasamy, M., Velayutham, T., and Rajeswar, J. (2011). Inv A gene specific PCR for detection of Salmonella from broilers. Vet. World 4, 562-564. doi: 10.5455/vetworld.2011.562-564

Shi, J., Chan, C., Pang, Y., Ye, W., Tian, F., Lyu, J., et al. (2015). A fluorescence resonance energy transfer (FRET) biosensor based on graphene quantum dots (GQDs) and gold nanoparticles (AuNPs) for the detection of mecA gene sequence of Staphylococcus aureus. Biosens. Bioelectron. 67, 595-600. doi: 10. 1016/j.bios.2014.09.059

Techathuvanan, C., Draughon, F. A., and D'Souza, D. H. (2011). Comparison of reverse transcriptase PCR, reverse transcriptase loop-mediated isothermal amplification, and culture-based assays for Salmonella detection from pork processing environments. J. Food Prot. 74, 294-301. doi: 10.4315/0362-028X. JFP-10-306

Unser, S., Bruzas, I., He, J., and Sagle, L. (2015). Localized surface plasmon resonance biosensing: current challenges and approaches. Sensors (Basel) 15, 15684-15716. doi: 10.3390/s150715684

Wu, F., Yuan, H., Zhou, C., Mao, M., Liu, Q., Shen, H., et al. (2015). Multiplexed detection of influenza A virus subtype H5 and H9 via quantum dot-based immunoassay. Biosens. Bioelectron. 77, 464-470. doi: 10.1016/j.bios.2015. 10.002

Wu, X., Liu, H., Liu, J., Haley, K. N., Treadway, J. A., Larson, J. P., et al. (2003). Immunofluorescent labeling of cancer marker Her2 and other cellular targets 
with semiconductor quantum dots. Nat. Biotechnol. 21, 41-46. doi: 10.1038/ nbt764

Yang, R., Jin, J., Chen, Y., Shao, N., Kang, H., Xiao, Z., et al. (2008). Carbon nanotube-quenched fluorescent oligonucleotides: probes that fluoresce upon hybridization. J. Am. Chem. Soc. 130, 8351-8358. doi: 10.1021/ja800604z

Zahraei Salehi, T., Mahzounieh, M., and Saeedzadeh, A. (2005). Detection of InvA Gene in Isolated Salmonella from Broilers by PCR Method. Int. J. Poult. Sci. 4, 557-559. doi: 10.3923/ijps.2005.557.559

Zhang, H., Zhang, H., Aldalbahi, A., Zuo, X., Fan, C., and Mi, X. (2016). Fluorescent biosensors enabled by graphene and graphene oxide. Biosens. Bioelectron. 89, 96-106. doi: 10.1016/j.bios.2016.07.030

Zheng, X. T., Ananthanarayanan, A., Luo, K. Q., and Chen, P. (2015). Glowing graphene quantum dots and carbon dots: properties, syntheses, and biological applications. Small 11, 1620-1636. doi: 10.1002/smll.201 402648

Conflict of Interest Statement: The authors declare that the research was conducted in the absence of any commercial or financial relationships that could be construed as a potential conflict of interest.

Copyright (c) 2017 Guo, Chan, Chen and Zeng. This is an open-access article distributed under the terms of the Creative Commons Attribution License (CC BY). The use, distribution or reproduction in other forums is permitted, provided the original author(s) or licensor are credited and that the original publication in this journal is cited, in accordance with accepted academic practice. No use, distribution or reproduction is permitted which does not comply with these terms. 